\title{
Trabajo conjunto desde las universidades para el futuro del país
}

La investigación y creación de nuevo conocimiento en todas las áreas del saber es la clave de la innovación para soñar y avanzar hacia el mejoramiento de las condiciones de vida de las personas. La investigación y la innovación puede ser de carácter social, tecnológico, culturales, de diseño y negocios. Cierto tipo de innovación necesita un fuerte desarrollo de investigación y, en el área científico-tecnológica, importantes inversiones. La innovación entrega un nuevo valor a la creación, es un proceso que requiere de investigadores, inventores y diseñadores de nuevo conocimiento y tecnologías y, de manera esencial, requiere de emprendedores que lleven estos avances e inventos a la sociedad, transfiriendo el nuevo conocimiento. Aquí se plantea el gran desafío del trabajo conjunto e interdisciplinario.

En esta cadena del desarrollo, el rol de las universidades resulta crucial. En nuestro país, más del 95\% de la investigación se realiza en las universidades y para aumentar nuestro aporte en innovación es preciso conectar mundos que están separados; conectar a los investigadores con los emprendedores, para que en conjunto puedan crear y entregar valor en las diferentes áreas que la población necesita. Se requiere de una investigación cuya base sea la dignidad de la persona y su desarrollo integral. Para esto la mirada debe ser amplia e inclusiva de todas las disciplinas, donde se incluya a las ciencias sociales, a las humanidades, el arte y a todas las disciplinas que impactan directamente en el bienestar de la persona, en su desarrollo y felicidad. Debemos propiciar una mayor interacción y eliminar aquellas barreras que separan a grupos que hoy no se conocen lo suficiente. Para esto, si queremos que la innovación juegue un rol central en el desarrollo de Chile, se necesitan investigadores y futuros profesionales impregnados de una cultura innovadora e interdisciplinaria, dispuestos a mover los límites disciplinares, geográficos y simbólicos desde los cuales hemos estado trabajando hasta ahora.

En la búsqueda de un mundo mejor, a diario, nos vemos interpelados a dar soluciones a situaciones más amplias y complejas, cuyo conocimiento se desarrolla en las fronteras disciplinarias. Esto nos lleva a hacer investigación con un enfoque en que converjan las diferentes disciplinas, para permitir así una mirada más profunda a estos temas complejos. Las diferentes visiones iluminan la discusión. Organizadas en centros interdisciplinarios, estas investigaciones en muchos casos se transfieren a soluciones innovadoras y permiten potenciar emprendimientos que juegan un rol clave en el desarrollo del país. En un proyecto educativo moderno, debemos abordar temas que incluyen la interacción de variadas disciplinas. Algunos ejemplos de este trabajo interdisciplinario enfocado en la innovación forman parte de proyectos reales que actualmente se desarrollan en universidades complejas, como la UC. Hay biólogos trabajando con ingenieros y médicos para dar una respuesta a los desafíos de la bioingeniería; periodistas interactuando con sociólogos e ingenieros para entender el impacto de las redes sociales; urbanistas, sociólogos, historiadores, arquitectos y artistas para el adecuado cuidado del patrimonio, entre muchos otros. La formación y trabajo de los Centros dan cuenta de este esfuerzo.

Algunos de estos centros, generados al alero de numerosas universidades del mundo, dan cuenta de una fructífera interacción entre el quehacer universitario, el mundo privado y el público, que permiten generar retroalimentaciones positivas en proyectos de innovación e iniciativas de emprendimiento interdisciplinarias, de alto impacto económico, social, cultural y artístico.

En un mundo cada día más globalizado la interacción es la regla. Sin embargo, no basta solo con la interacción de las diversas disciplinas, también es necesaria la asociatividad entre las instituciones. Por medio de esta es posible generar sinergias, compartir conocimiento, formar capital humano avanzado y desarrollar proyectos comunes. En la actualidad, son cinco o seis universidades las que realizan la mayor parte de la investigación en nuestro país, lo que presenta un gran potencial de colaboración. En este sentido, cobra relevancia la creación de grandes centros universitarios de clase mundial, donde colaboren instituciones del ámbito privado, público y empresarial, con equipamiento científico y tecnológico a la altura y una cultura de trabajo en equipo y de asociatividad, a lo que el 


\section{Sánchez}

Estado puede contribuir mediante financiamiento para incentivar este tipo de actividades. Así también nuestra responsabilidad incluye universidades que tienen menor desarrollo, estatales, de función pública y privada, para poder trabajar y apoyarlas en sus procesos. Lo anterior no debe quedarse en nuestras fronteras, el trabajo en redes internacionales es vital y muy fructífero.

El desarrollo de un país depende de la visión que tenga la sociedad para invertir en investigación, generar nuevo conocimiento y realizar transferencia de sus resultados. Coherente con este planteamiento, se hace necesario consolidar el trabajo interdisciplinario al interior de la universidad, incorporando a los estudiantes de pre y postgrado a la cadena de innovación y, como institución, dar el ejemplo de interactuar con otras entidades nacionales y extranjeras, de lo contrario el desarrollo de la innovación será limitado. Nuestro desafío como universidades complejas debiera ser justamente incrementar el volumen y calidad de la investigación y conectarla efectivamente con las necesidades del país. Nos debiera interesar que el conocimiento que se desarrolle sea transferido a la sociedad a través de programas concretos, donde se pueda practicar alianzas virtuosas entre la academia, el Estado y la empresa privada. Para ello necesitamos científicos en redes, profesionales con alta preparación técnica, capaces de identificar, comprender y e internalizar nuevos conocimientos con potencial de innovación.

En la medida que tengamos la voluntad de trabajar en colaboración, con una visión interdisciplinaria y movidos por la búsqueda de nuevo conocimiento que genere soluciones innovadoras a los problemas de nuestra sociedad, seremos un real aporte al mejoramiento de la calidad de vida de las personas.

\section{Dr. Ignacio Sánchez}

Rector

Pontificia Universidad Católica de Chile

Santiago, Mayo 2016 